\title{
Potential antidiabetic and antioxidant activities of a heliangolide sesquiterpene lactone isolated from Helianthus annuus L. leaves
}

SAMUEL O. ONOJA ${ }^{1, *}$

CHARLES O. NNADI ${ }^{2}$

SAMUEL C. UDEM ${ }^{3}$

ARUH O. ANAGA ${ }^{3}$

${ }^{1}$ Department of Veterinary Physiology

and Pharmacology

Michael Okpara University of Agriculture Umudike, PMB 7267 Umuahia, Nigeria

${ }^{2}$ Department of Pharmaceutical and Medicinal Chemistry

University of Nigeria Nsukka, 410001

Enugu State, Nigeria

${ }^{3}$ Department of Veterinary Physiology

and Pharmacology

Faculty of Veterinary Medicine

University of Nigeria, Nsukka

410001 Enugu State, Nigeria
Accepted June 9, 2019

Published online August 20, 2019

\begin{abstract}
Heliangolide is a naturally occurring sesquiterpene lactone and its derivatives are biologically active compounds present in most medicinal plants. This study evaluated the antioxidant and antidiabetic properties of a heliangolide sesquiterpene lactone isolated from Helianthus annuus L. leaves. The heliangolide sesquiterpene lactone was isolated through a combination of solvent-solvent partitioning, column chromatography, thin layer chromatography and high-performance liquid chromatography techniques. The antioxidant activity of the compound was evaluated using 2,2-diphenyl-1-picrylhydrazyl (DPPH) and nitric oxide radical scavenging assays while the antidiabetic effects were investigated in alloxan-induced diabetic rats. The heliangolide derivative at the concentration of $954.2 \mu \mathrm{mol} \mathrm{L}{ }^{-1}$ showed $23.7 \%$ DPPH and $26 \%$ nitric oxide radical inhibitions compared with 96.6 and $50.9 \%$, resp., displayed by the controls $\left(2,271.2 \mu \mathrm{mol} \mathrm{L}{ }^{-1}\right)$. It also reduced the fasting blood glucose (FBG) levels in a time-dependent manner. The highest activity was recorded within $6 \mathrm{~h}$ post-treatment at $0.2 \mathrm{mmol} \mathrm{kg}^{-1} \mathrm{bm}$. The heliangolide derivative exhibited significant $(p<0.05)$ antioxidant and antidiabetic properties and provides a basis for further development of constituents of Helianthus annuus leaves for the management of such diseases.
\end{abstract}

Keywords: Helianthus annuus, heliangolide derivative, antidiabetic, antioxidant

Diabetes mellitus is a chronic metabolic disease that is caused by partial or complete insulin deficiency and/or insulin resistance (1). It is usually accompanied by renal failure, coronary artery disease, blurred vision, neuropathy and impaired wound healing that may predispose to limb amputation (1). These diabetes complications are attributed to hyperglycemia, hyperlipidemia and oxidative stress which often characterize diabetes mellitus (2). Type 2 diabetes is the most common form of diabetes and constitutes about 90

\footnotetext{
*Correspondence; e-mail: samonreal@yahoo.com; onoja.samuel@mouau.edu.ng
} 
$\%$ of diabetes cases. It is clinically managed by chemotherapy with hypoglycemic drugs such as biguanides, sulphonylurea, amylin mimetics, alpha-glucosidase inhibitors, glitazones and meglitinides (3). These antidiabetic drugs, despite being expensive and not readily available, have adverse side-effects that have significantly reduced their clinical usage.

As a result, the search for new hypoglycemic drugs with reduced side-effects is ongoing in many laboratories worldwide (4). Several medicinal plants-derived bioactive compounds have shown interesting potential against type 2 diabetes (5). Heliangolide, a known sesquiterpene lactone, is a bioactive secondary metabolite of medicinal plants with diverse pharmacological activities (6). It was first isolated as a constituent of Saussurea lappa root (7) and also in association with other sequiterpene lactones in many other plants, especially those belonging to the family Asteraceae $(8,9)$. Other isolated derivatives of sesquiterpene lactones are dihydrocostunolide, dehydrocostulactone, isodihydrocostunolide, $\beta$-cyclocostunolide, 9 $\beta$-acetoxycostunolide and several 13-amino derivatives (10-12). Some of their activities include antidiabetic, antioxidant, antiinflammatory, hypolipidemic, anticancer and antifungal properties $(13,14)$.

H. annuus Linn. (family Asteraceae) is relevant in ethnopharmacology as a diuretic, antidiabetic, expectorant, gastrointestinal stimulant, antimicrobial agent, analgesic agent, etc. $(15,16)$. Antidiabetic activity of the crude methanolic extract of $H$. annuus has been reported by Onoja and Anaga (17) but the bioactive antidiabetic principle is yet to be identified. This study aims to isolate and characterize the major antidiabetic principle(s) of $H$. annuus.

\section{EXPERIMENTAL}

\section{Reagents and chemicals}

Methanol, HPLC grade, was obtained from Fischer Chemicals (UK). $n$-hexane, chloroform, $n$-butanol, $p$-anisaldehyde, sulfuric acid, ethyl acetate, $N$-alpha-naphthyl-ethylenediamine, phosphoric acid, sulfanilic acid, sodium nitroprusside, silica gel and d-chloroform, $99.8 \% \mathrm{D}$ and 2,2-diphenyl-1-picrylhydrazyl were procured from Merck KGaA (Germany), Millipore water for UHPLC/+ESI-QqTOFMS/MS measurement was LC-MS grade (HiPerSolv CHROMANORM, VWR International, Belgium) and glibenclamide (GNC, Nigeria). Unless otherwise stated, all the reagents were used without purification.

\section{Plant collection and extract preparation}

The leaves of H. annuus were collected in June 2016 from the wild in Nsukka, Enugu state, Nigeria, and authenticated by a plant taxonomist in the Department of Plant Science and Biotechnology, University of Nigeria, Nsukka. It was deposited in the departmental herbarium with voucher number, $\mathrm{UNN} / \mathrm{VPP} / 2012 / 2$. The leaves were dried under a shed at ambient temperature $\left(25-27^{\circ} \mathrm{C}\right)$. The extract of $H$. annuus was prepared using the cold maceration method in $80 \%$ hydromethanol as described by Onoja and Anaga (17) and was referred to as hydromethanolic extract of $H$. annuus leaves (HEHAL). 


\section{Solvent-solvent separation of HEHAL}

The HEHAL was subject to solvent-solvent partitioning (10 $\mathrm{g}$ in $100 \mathrm{~mL}$ of $80 \%$ aqueous methanol) with $n$-hexane, chloroform, ethyl acetate and $n$-butanol using a separating funnel as described by Bibi et al. (18) (Fig. 1).

\section{Column chromatographic separation of $\mathrm{n}$-butanol fraction}

The $n$-butanol insoluble portion ( $2.8 \mathrm{~g})$ formed on evaporation to dryness was dissolved in the mobile phase (ethyl acetate/methanol, 9:1) and introduced to the silica gel 60 (0.06-0.20 mm particles) slurry packed column, $90 \times 8 \mathrm{~cm}$ (GE Healthcare Europe $\mathrm{GmbH}$, Germany), extract/silica gel ratio, 1:70, at room temperature. The fraction was eluted with a gradient of mobile phase consisting of ethyl acetate and methanol starting with $90 \%$ ethyl acetate and gradually increasing the ratio of methanol up to $50 \%$ at a flow rate of 0.5 $\mathrm{mL} \mathrm{min}^{-1}$.

\section{Thin layer chromatographic analysis of fractions}

Analytical TLC was performed on pre-coated silica gel $60 \mathrm{~F}_{254}$ plates, $20 \times 10 \mathrm{~cm}$ (Merck $\mathrm{KGaA} \mathrm{GmbH}$, Germany) with various solvent systems consisting of ethyl acetate and methanol in appropriate ratios optimized for each experimental run at room temperature. The plates, developed over $8 \mathrm{~cm}$ distance, were visualized under UV light at 254/365 nm and sprayed with anisaldehyde-sulphuric acid detecting reagent. The collected eluates (20-25 mL) from the column chromatographic separation of $n$-butanol fraction were

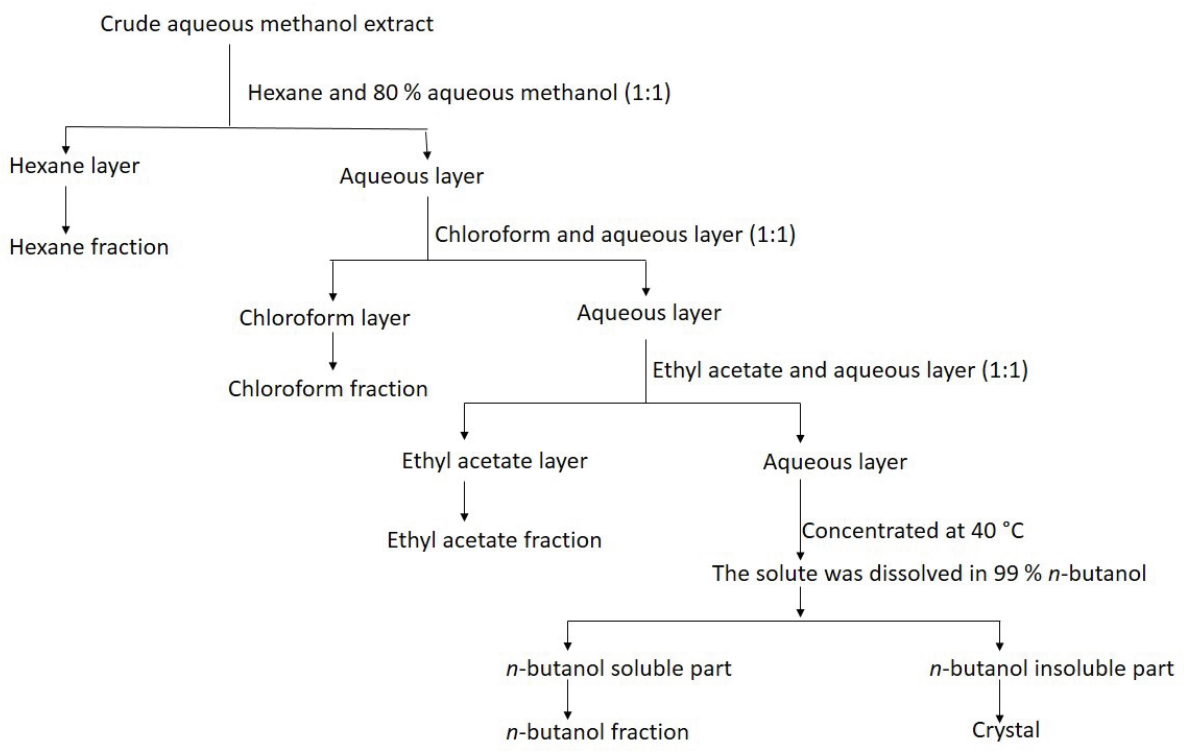

Fig. 1. Fractionation scheme of HEHAL (18). 
analysed by TLC at predetermined intervals and subsequently pooled into six sub-fractions (tubes 37-189) based on their TLC profiles as follows: sub-fraction 1, $380 \mathrm{mg}$ (tubes 37-56), sub-fraction 2, $850 \mathrm{mg}$ (tubes 59-98), sub-fraction 3, $508 \mathrm{mg}$ (tubes 100-128), subfraction 4, $330 \mathrm{mg}$ (tubes 131-147), sub-fraction 5, $105 \mathrm{mg}$ (tubes 152-177) and sub-fraction 6, $120 \mathrm{mg}$ (tubes 178-189).

\section{Preparative HPLC isolation of compounds}

Sub-fraction 2 (850 mg), obtained from the column chromatographic separation, was further separated and purified by preparative HPLC to yield a $76 \mathrm{mg}$ of pure compound representing the dominant constituent of the most active sub-fraction. Isolation of the compound was done using the preparative HPLC system (Jasco, Germany, pump PU-2087 plus, diode array detector MD 2018 plus, a column thermostat CO 2060 plus, autosampler AS 2055 plus, LC Net II ADC Chromatography Data Solutions). Separations were performed on a reverse phase column Reprosil $100 \mathrm{C}-18(250 \times 20 \mathrm{~mm}, 5 \mu \mathrm{m})$ using the binary gradient of the mobile phase (water and methanol) at a flow rate of $10 \mathrm{~mL} \mathrm{~min}^{-1}$ and column temperature of $40{ }^{\circ} \mathrm{C}$ with the sample injection loop of $1000 \mu \mathrm{L}$. The mobile phase

b)
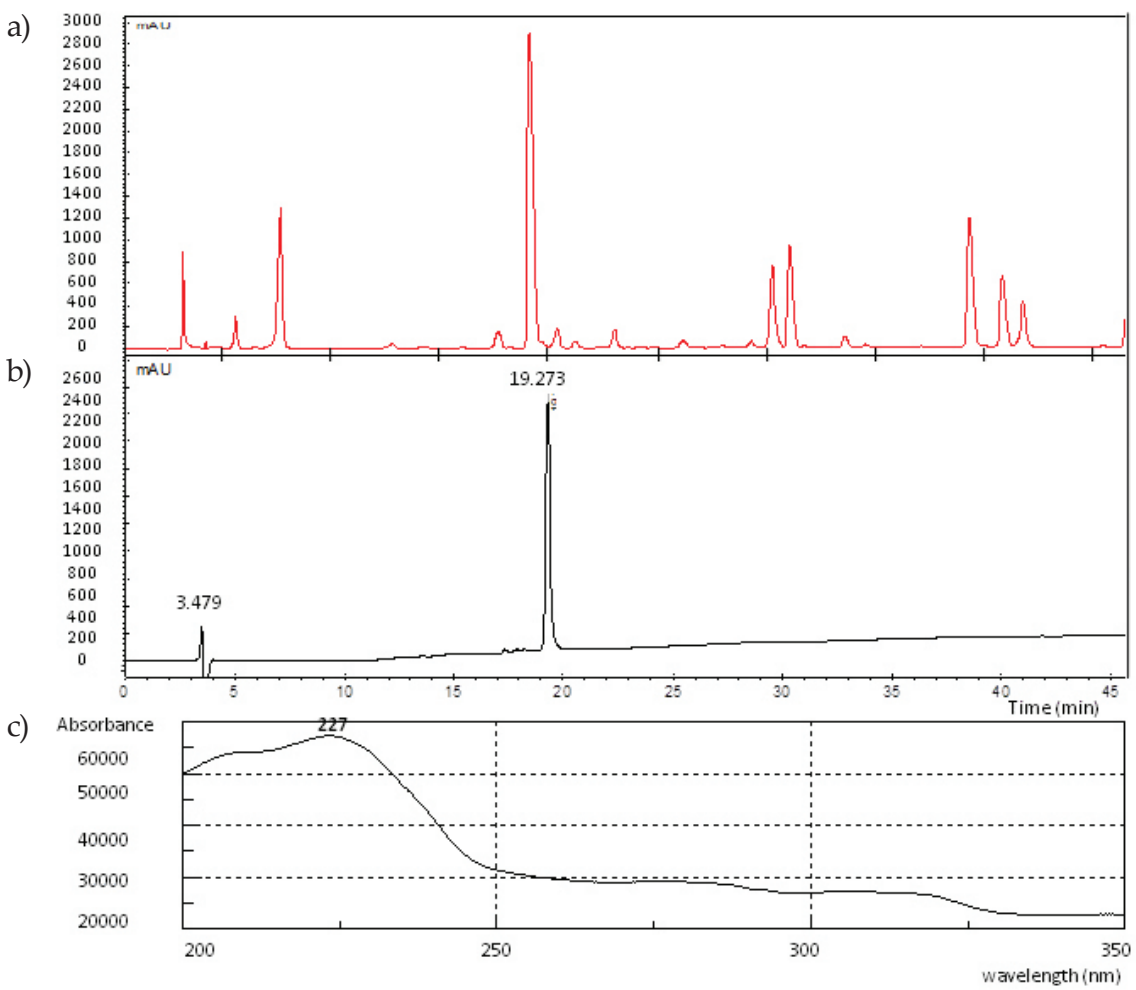

Fig. 2. Preparative HPLC chromatograms of: a) CC sub-fraction 2, b) isolated heliangolide derivative, c) UV spectrum of heliangolide derivative. 
optimized for the preparative HPLC consisted of water and methanol in gradient conditions as follows: $60-30 \%$ of water (10 $\mathrm{min}), 30-20 \%$ water (5 min), $20-10 \%$ water ( $5 \mathrm{~min}$ ), $10-0 \%$ water $(10 \mathrm{~min})$ and $0 \%$ water $(10 \mathrm{~min})$ and additional 5 minutes to return the system to the initial mobile phase. The retention time $\left(t_{\mathrm{R}}\right)$ of the isolated compound under these conditions was 19.273 min as shown in Fig. 2.

\section{Structural characterization of the isolated compound}

1D-NMR spectra, proton $\left({ }^{1} \mathrm{H}\right)$ and carbon-13 $\left({ }^{13} \mathrm{C}\right)$ and 2D-NMR proton-proton correlation spectroscopy $\left({ }^{1} \mathrm{H} /{ }^{1} \mathrm{H}\right.$ COSY $)$, proton-carbon-13 heteronuclear single quantum correlation $\left({ }^{1} \mathrm{H} /{ }^{13} \mathrm{C} \mathrm{HSQC}\right)$, and proton-carbon-13 heteronuclear multiple bond correlation $\left({ }^{1} \mathrm{H} /{ }^{13} \mathrm{C}\right.$ HMBC) were recorded on the Agilent DD2 $600 \mathrm{MHz}$ spectrometer (Agilent Technologies, USA) at $25^{\circ} \mathrm{C}$. Samples were dried overnight in a desiccant-filled Desaga drying apparatus (Desaga, Germany). Solutions of the samples were typically prepared in deuterated chloroform $\left(\mathrm{CDCl}_{3}\right)$. The recorded spectra were referenced to the solvent signals of ${ }^{1} \mathrm{H} 7.260$ ppm and ${ }^{13} \mathrm{C} 77.000 \mathrm{ppm}\left(\mathrm{CDCl}_{3}\right)$ and processed with MestRENOVA v. 11 (Mestrelab Research, Chemistry Software Solutions, USA) software.

${ }^{1} \mathrm{H}$ NMR data are reported indicating the chemical shift $(d)$ in ppm, the integer (in cases where signals represent more than one proton, e.g., $2 \mathrm{H}$ or $3 \mathrm{H})$, the multiplicity $(s$, singlet; $d$, doublet; $t$, triplet; $q$, quartet; $m$, multiplet; $b r$, broad; $d d$, doublet of doublets, etc.) and the coupling constant(s) $(J)$ in $\mathrm{Hz} .{ }^{13} \mathrm{C}$ NMR data are reported indicating only the chemical shifts $(\delta, \mathrm{ppm})$. All the spectra data were compared with the library data.

\section{Antioxidant activity}

The heliangolide derivative in the concentration range 59.6-954.2 $\mu \mathrm{mol} \mathrm{L}^{-1}$ was used in the following tests. Tests were performed in triplicate and ascorbic acid (142.0-2,271.2 $\mu \mathrm{mol} \mathrm{L}{ }^{-1}$ ) was used as positive control.

2,2-Diphenyl-1-picrylhydrazyl (DPPH) radical scavenging assay. - The DPPH (Sigma Aldrich, USA) scavenging property of the compound was evaluated as modified by Onoja et al. (19). DPPH is a stable violet coloured free radical that has the capacity to react with a hydrogen donor to form a stable yellow diamagnetic compound at room temperature within 30 minutes.

Nitric oxide radical inhibition activity. - The Griess reaction method as described by Marcocci et al. (20) was used to evaluate the nitric oxide radical inhibition activity of the heliangolide derivative. The protocol is hinged on the principle that in an aqueous medium and under physiological $\mathrm{pH}$, sodium nitroprusside generates nitric oxide which can be estimated indirectly with Griess reagent.

\section{Experimental animals}

Eighteen 10-weeks old male albino Wistar rats (110-120 g) were used for the study. They were housed in aluminum cages in a well-ventilated room at ambient temperature $\left(25-27^{\circ} \mathrm{C}\right)$ and natural light/darkness cycle. The rats were acclimatized for 2 weeks and the experimental procedures were approved by the University of Nigeria Nsukka, Animal Ethical Committee. 


\section{Antidiabetic activity}

Diabetes was induced in 18 albino Wistar rats with alloxan $\left(160 \mathrm{mg} \mathrm{kg}^{-1} \mathrm{bm}\right)$ as described by Sebai et al. (21). The diabetic rats were randomly assigned to 3 groups $(n=6)$ and received $5 \%$ Tween-20 $\left(5 \mathrm{~mL} \mathrm{~kg}^{-1} \mathrm{bm}\right)$, glibenclamide $\left(4 \mu \mathrm{mol} \mathrm{kg}^{-1} \mathrm{bm}\right)$ and heliangolide derivative $\left(0.2 \mathrm{mmol} \mathrm{kg}^{-1} \mathrm{bm}\right)$, resp. All compounds were administered orally. The fasting blood glucose (FBG) was determined after 1, 3, 6 and $24 \mathrm{~h}$ in the blood collected from the tail vein.

\section{Statistical analysis}

Data obtained presented as mean \pm SEM was analysed using one-way analysis of variance (ANOVA) and post-hoc comparisons were carried out using Dunnett's test in SPSS version 20. Differences at $p<0.05$ were considered significant.

\section{RESULTS AND DISCUSSION}

\section{Characterization of heliangolide}

The heliangolide sesquiterpene lactone was isolated from a column sub-fraction 2 using preparative HPLC as a white crystalline compound. The ${ }^{13} \mathrm{C} /{ }^{1} \mathrm{H}$ HSQC spectra (Table I) revealed a $\mathrm{C}_{22}$ compound comprised of $3 \mathrm{CH}_{3}$ (methyl), $4 \mathrm{CH}_{2}$ (methylene), $8 \mathrm{CH}$ (methine) and $7 \mathrm{Cq}$ (quaternary carbons) with the elemental formula of $\mathrm{C}_{22} \mathrm{H}_{26} \mathrm{O}_{8}$ deduced

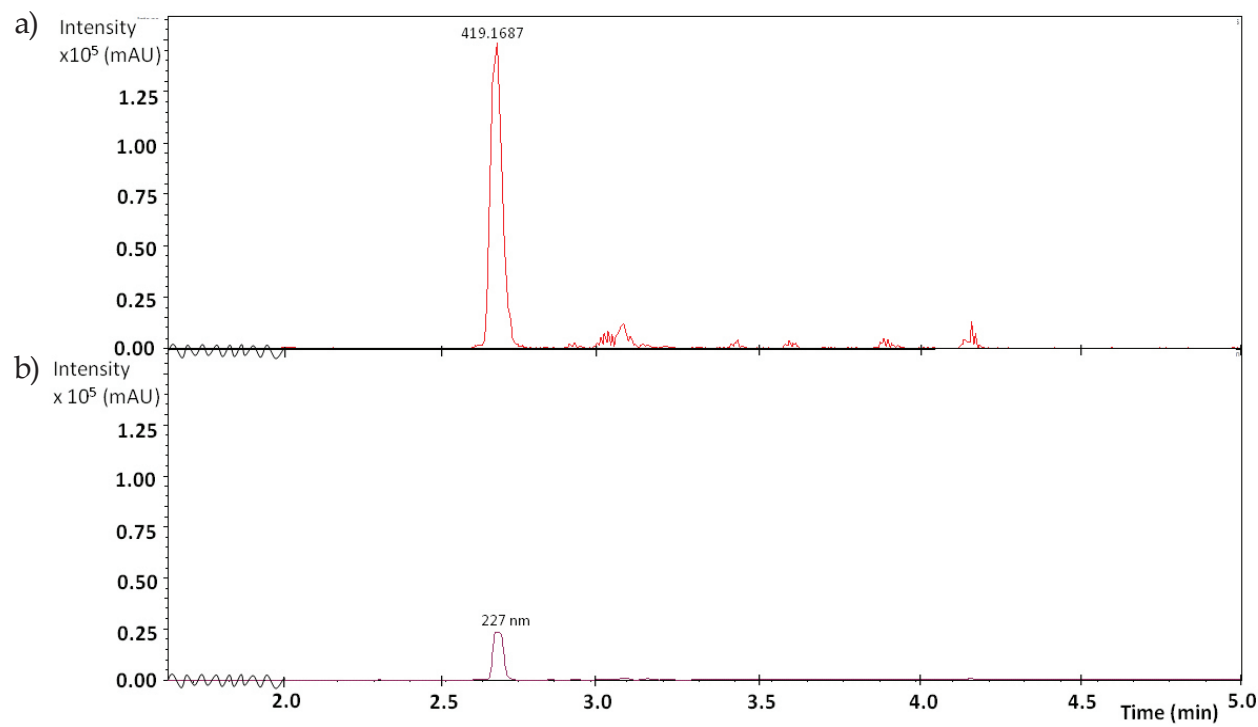

Fig. 3. UHPLC/+ESI-QqTOF-MS/MS of heliangolide derivative $\left(0.1 \mathrm{mg} \mathrm{mL}^{-1}\right)$. a) Upper panel indicates a base peak MS chromatogram, $\mathrm{m} / \mathrm{z}$ 50-1000; b) lower panel shows a base peak UV chromatogram in the range $200-400 \mathrm{~nm}$. 
Table I. Spectral data of the isolated heliangolide derivative

\begin{tabular}{|c|c|c|c|c|c|}
\hline $\begin{array}{l}\text { Carbon } \\
\text { position }\end{array}$ & $\begin{array}{l}{ }^{13} \mathrm{C}, \delta \\
(\mathrm{ppm})\end{array}$ & $\begin{array}{l}{ }^{1} \mathrm{H}(\delta, \mathrm{ppm}) \\
\text { mult., } J(\mathrm{~Hz})\end{array}$ & $\begin{array}{l}{ }^{13} \mathrm{C} /{ }^{1} \mathrm{H} \\
\mathrm{HSQC}\end{array}$ & ${ }^{13} \mathrm{C} /{ }^{1} \mathrm{H}$ HMBC & ${ }^{1} \mathrm{H} /{ }^{1} \mathrm{H} \cos Y$ \\
\hline 1 & 103.5 & $6.14,1 \mathrm{H}$, br s, & $-\mathrm{CH}-$ & - & $\mathrm{H}-5^{\prime}$ \\
\hline 2 & 29.6 & $\begin{array}{l}2.28,1 \mathrm{H}, \mathrm{m} \\
2.70,1 \mathrm{H}, \mathrm{m}\end{array}$ & $-\mathrm{CH}_{2-}^{-}$ & $C-5, C-10$ & H-3, H-5, H-8 \\
\hline 3 & 79.4 & $5.26,1 \mathrm{H}$, br d, 11 & $-\mathrm{CH}-$ & - & H-9 \\
\hline 4 & 137.2 & - & $-\mathrm{C}-$ & - & - \\
\hline 5 & 126.3 & $5.17,1 \mathrm{H}, \mathrm{br} \mathrm{d}, 6.5$ & $-\mathrm{CH}-$ & C-15, C-7, C-3 & H-6, H-9, H-2 \\
\hline 6 & 75.6 & $5.86,1 \mathrm{H}, \mathrm{m}$ & $-\mathrm{CH}-$ & - & H-5 \\
\hline 7 & 48.5 & $2.95,1 \mathrm{H}, \mathrm{br} \mathrm{s}$ & $-\mathrm{CH}-$ & C-13, C-5, C-11, C-12 & H-5 \\
\hline 8 & 79.3 & $5.24,1 \mathrm{H}, \mathrm{dd}, 2.3,7.0$ & $-\mathrm{CH}-$ & $C-5$ & H-9 \\
\hline 9 & 43.6 & $\begin{array}{c}2.45,1 \mathrm{H}, \mathrm{m} \\
2.72,1 \mathrm{H}, \mathrm{br} \mathrm{d}, 2.1\end{array}$ & $-\mathrm{CH}_{2-}^{-}$ & C-10, C-5 & H-8 \\
\hline 10 & 135.2 & - & $-\mathrm{C}-$ & - & - \\
\hline 11 & 137.2 & - & $-\mathrm{C}-$ & - & - \\
\hline 12 & 169.6 & - & $-\mathrm{C}-$ & - & - \\
\hline 13 & 125.2 & $\begin{array}{l}5.78,1 \mathrm{H}, \mathrm{d}, 12.2 \\
6.36,1 \mathrm{H}, \mathrm{d}, 12.3\end{array}$ & $-\mathrm{CH}_{2-}^{-}$ & C-7, C-8, C-12, C-11 & $\mathrm{H}-7$ \\
\hline 14 & 19.6 & $1.79,3 \mathrm{H}, \mathrm{br} \mathrm{s}$ & $-\mathrm{CH}_{3}$ & C-9 & - \\
\hline 15 & 23.2 & $1.82,3 \mathrm{H}, \mathrm{br} \mathrm{s}$ & $-\mathrm{CH}_{3}$ & C-3, C-5, C-4 & - \\
\hline $1^{\prime}$ & 161.2 & - & $-\mathrm{C}-$ & - & - \\
\hline $2^{\prime}$ & 137.4 & $6.60,1 \mathrm{H}, \mathrm{d}, 7.1$ & $-\mathrm{CH}-$ & $C-5^{\prime}, C-1^{\prime}$ & $\mathrm{H}-5^{\prime}$ \\
\hline $3^{\prime}$ & 137.3 & $6.60,1 \mathrm{H}, \mathrm{d}, 7.5$ & $-\mathrm{CH}-$ & $C-5^{\prime}, C-1^{\prime}$ & $\mathrm{H}-5^{\prime}$ \\
\hline $5^{\prime}$ & 72.5 & $\begin{array}{l}4.65,1 \mathrm{H}, \mathrm{s} \\
4.82,1 \mathrm{H}, \mathrm{s}\end{array}$ & $-\mathrm{CH}_{2-}^{-}$ & $C-1, C-1^{\prime}, C-2^{\prime}$ & H-2', H-1, \\
\hline $1^{\prime \prime}$ & 169.9 & - & $-\mathrm{C}-$ & & - \\
\hline $2^{\prime \prime}$ & 21.4 & $2.09,3 \mathrm{H}, \mathrm{s}$ & $-\mathrm{CH}_{3}$ & $C-3, C-1^{\prime \prime}$ & - \\
\hline $3^{\prime \prime}$ & 169.5 & - & $-\mathrm{C}-$ & & - \\
\hline
\end{tabular}

All measurements were done in deuterated chloroform, $\mathrm{CDCl}_{3}$, at $600 \mathrm{MHz}\left({ }^{1} \mathrm{H}\right)$ and $150 \mathrm{MHz}\left({ }^{13} \mathrm{C}\right)$.

COSY - proton-proton correlation spectroscopy, HMBC - carbon-proton heteronuclear multiple bond correlation, HSQC - carbon-proton heteronuclear single quantum correlation

from the +ESI-QqTOF mass spectrum (Fig. 3). The ${ }^{1} \mathrm{H}$ signals at $\delta 1.82-1.79 \mathrm{ppm}$ were due to the methyl protons attached to the cyclodecene ring, whereas the methyl proton of methoxylate ion was assigned to a singlet at $\delta 2.09 \mathrm{ppm}$. The signal at $\delta 6.36-6.37 \mathrm{ppm}$ was attributed to the furan protons, whereas the methylene proton $\left(=\mathrm{CH}_{2}\right)$ and the hydroxyl proton $(-\mathrm{OH})$ attached to the furan were assigned to $\delta 5.78(\mathrm{~d}, J=12.2 \mathrm{~Hz})$ and $\delta 6.60 \mathrm{ppm}$ (d, $J=7.5 \mathrm{~Hz}$ ) resp. (Table I). A characteristic downfield signal at $\delta 5.76 \mathrm{ppm}$, br doublet, 


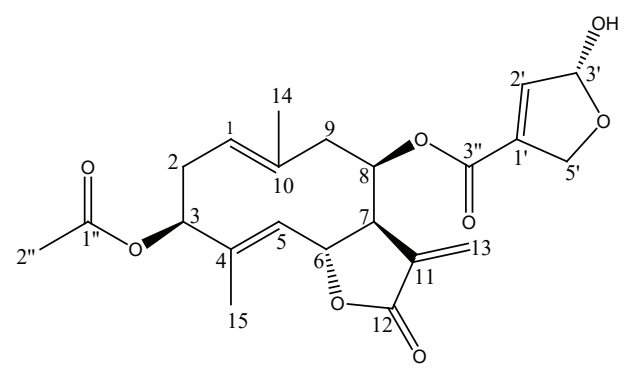

Fig. 4. Chemical structure of the isolated heliangolide derivative (20-dehydroeucannabinolide); (UHPLC/+ESI-QqTOF MS: $t_{\mathrm{R}} 2.665 \mathrm{~min}$, MS ( $\left.\mathrm{m} / \mathrm{z}\right)$ : $419.1687[\mathrm{M}+\mathrm{H}]^{+}$; calculated for $\mathrm{C}_{22} \mathrm{H}_{27} \mathrm{O}_{8}{ }^{+}: 419.4458$; $\mathrm{UV} \lambda_{\max }=220 \mathrm{~nm}$.

suggests a shielded proton signal by the -OCOMe group. The large coupling constant of $\mathrm{H}-3(J=11 \mathrm{~Hz})$ is an indication of a diaxial spin-spin coupling with the axial position for $\mathrm{H}-3$ on the a-face and an equatorial $\beta$-orientation for the OCOMe group. The ${ }^{13} \mathrm{C} \mathrm{NMR}$ signals at $\delta 137.18-137.44 \mathrm{ppm}$ were attributed to furan carbons, $\delta 169.59-169.90 \mathrm{ppm}$ to carbonyl carbons (Table I). The ${ }^{1} \mathrm{H} /{ }^{1} \mathrm{H}$ COSY spectrum showed the intense correlation of proton signals at $\delta 5.25$ and 2.45 ppm for $\mathrm{H}-8$ and $\mathrm{H}-9$, resp., in addition to a weak correlation of H-7, $\delta 2.95$ and H-5, $\delta 5.17$ ppm. However, the two proton signal at $\delta 6.60, \mathrm{H}-2^{\prime} / \mathrm{H}-3^{\prime}$ showed significant correlation with the signal at $\delta 4.65, \mathrm{H}-5^{\prime}$ (Table I).

All the spectral evidence was in full agreement with the structure of a heliangolide lactone as shown in Fig. 3 and further confirmed with literature values of 20-dehydroeucannabinolide previously isolated from Disynnaphia multicrenulata (22). Interestingly, this is the first time this heliangolide derivative is to be reported in Helianthus annuus (Fig. 4). Sesquiterpene lactones are generally soluble in non-polar solvents, but the solubility of this derivative in a polar solvent could be attributed to the presence of hydroxyfuran and carboxylate $(12,23)$.

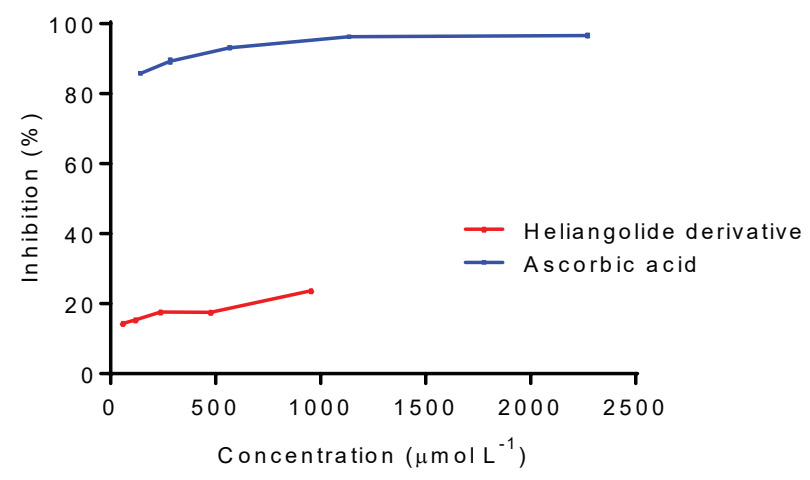

Fig. 5. DPPH radical scavenging activities of the heliangolide derivative. Data are expressed as mean \pm SEM, $n=3$. 


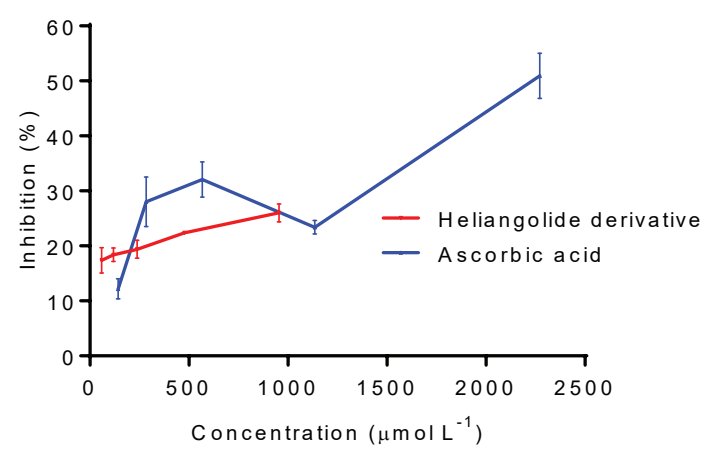

Fig. 6. Nitric oxide scavenging activities of heliangolide derivative. Data are expressed as mean \pm SEM, $n=3$.

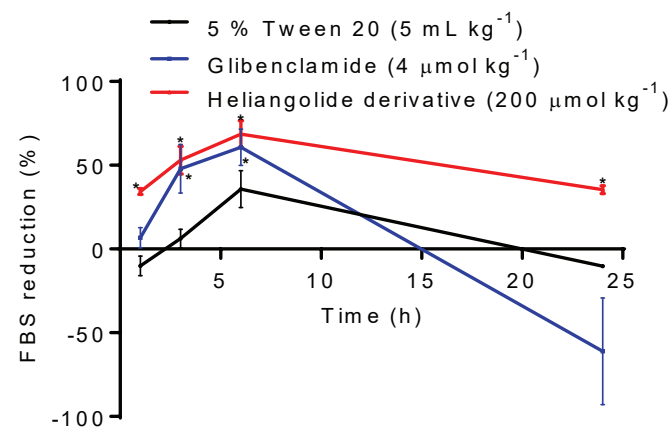

Fig. 7. Antidiabetic activities of the heliangolide derivative. Data are expressed as mean \pm SEM, $n=6$. Significant difference relative to $5 \%$ Tween-20 treated group: ${ }^{*} p<0.05$; FBS - fasting blood sugar level.

\section{Antioxidant activity of the heliangolide derivative}

Our preliminary results showed that the isolated compound had produced concentration-dependent inhibition of free radicals. At $954.2 \mu \mathrm{mol} \mathrm{L}{ }^{-1}$, it showed $23.7 \%$ DPPH (Fig. 5) and $26.0 \%$ nitric oxide (Fig. 6) radical inhibition compared with 96.6 and $50.9 \%$, resp., caused by ascorbic acid at 2,271.2 $\mu \mathrm{mol} \mathrm{L} \mathrm{L}^{-1}$. The $I C_{50}$ estimate of heliangolide against DPPH and nitric oxide radical is much higher than $950 \mu \mathrm{mol} \mathrm{L}^{-1}$ (expectedly $>3 \mathrm{mmol} \mathrm{L}^{-1}$ ), while the $I C_{50}$ of ascorbic acid against DPPH and nitric oxide radical is much lower than $140 \mu \mathrm{mol}$ $\mathrm{L}^{-1}$ and around $2 \mathrm{mmol} \mathrm{L}^{-1}$, resp. The isolated compound might exhibit free radical scavenging effects similar to the report of Eliza et al. (14), still markedly lower than that of ascorbic acid. All of this suggests that it can possibly mitigate the pathogenesis and complications of diabetes mellitus.

\section{Antidiabetic activity of the heliangolide derivative}

The heliangolide derivative $\left(200 \mathrm{mmol} \mathrm{kg}^{-1}\right)$ reduced the fasting blood glucose (FBG) level in a time-dependent manner. Statistically significant difference vs. control group $(p<$ 
0.05) was achieved already after an hour and maximum effect was obtained within $6 \mathrm{~h}$ post-treatment (Fig. 7), which made it comparable to that of glibenclamide $\left(4 \mathrm{mmol} \mathrm{kg}^{-1}\right)$.

This suggests that the compound might have reduced glucose absorption, increased glucose uptake by the liver and skeletal muscle and/or stimulated insulin release. An elevated level of tissue glycogen has been reported in sesquiterpene lactones-treated diabetic rats (24). Sesquiterpene lactones stimulate beta-cell regeneration and insulin production through the impaired expression of nitric oxide synthase (25). The promising scavenging of nitric oxide radical by the heliangolide derivative goes along this assumption.

The exo-methylene group on the lactone part of sesquiterpenes is required for cytotoxicity (26). This may imply that the derivative isolated in this study, having the intact exo-methylene group and promising antioxidant activity, could possess anticancer properties as well (9). The early and high percentage of FBS level reduction observed within $3 \mathrm{~h}$ $(53.0 \%)$ reaching maximum at $6 \mathrm{~h}(68.5 \%)$ and declining at $24 \mathrm{~h}(35.4 \%)$ was also significant in the heliangolide-treated group. This effect, like in the majority of antidiabetic chemotherapy, could require regular maintenance doses to keep the blood plasma levels within its therapeutic window. However, the antidiabetic activity of the tested heliangolide derivative was much lower than that of the reference drug, glibenclamide.

\section{CONCLUSIONS}

A heliangolide sesquiterpene lactone (20-dehydroeucannabinolide) was isolated from Helianthus annuus leaves for the first time. It exhibited promising antioxidant and antidiabetic activities and, therefore, the isolated compound might serve as the starting point in the development of new compounds against diabetes and diseases associated with ROS.

Acronyms, abbreviations, symbols. - FBG - fasting blood glucose, COSY - proton-proton correlation spectroscopy, DPPH - 2,2-diphenyl-1-picrylhydrazyl, GLB - glibenclamide, HMBC - carbonproton heteronuclear multiple bond correlation, HSQC - carbon-proton heteronuclear single quantum correlation.

Acknowledgements. - The authors are grateful to the management Institute of Pharmaceutical Biology and Phytochemistry (IPBP), University of Münster, PharmaCampus Corrensstraße 48, D-48149 Münster, Germany for granting us access their laboratory facilities to characterize the compound.

Supplementary material available upon request.

\section{REFERENCES}

1. A. Chawla, R. Chawla and S. Jaggi, Microvasular and macrovascular complications in diabetes mellitus: distinct or continuum?, Indian J. Endocr. Metab. 20 (2016) 546-551; https://doi. org $/ 10.4103 / 2230-8210.183480$

2. American Diabetes Association, Classification and diagnosis of diabetes: standards of medical care in diabetes - 2018, Diabetes Care 41 (Suppl. 1) (2018) S13-S27; https://doi.org/10.2337/dc18-S002

3. S. Asgary, M. Rafieian-Kopaei, F. Shamsi, S. Najafi and A. Sahebkar, Biochemical and histopathological study of the anti-hyperglycemic and anti-hyperlipidemic effects of cornelian cherry (Cor- 
nus mas L.) in alloxan-induced diabetic rats, J. Complement. Integr. Med. 11 (2014) 63-69; https://doi. org/10.1515/jcim-2013-0022

4. G. L. Khatik, A. K. Datusalia, W. Ahsan, P. Kaur, M. Vyas, A. Mittal and S. K. Nayak, A retrospect study on thiazole derivatives as the potential antidiabetic agents in drug discovery and developments, Curr. Drug Discov. Technol. 15 (2018) 163-177; https://doi.org/10.2174/157016381466617091513 4018

5. S. Gothai, P. Ganesan, S. Y. Park, S. Fakurazi, D. K. Choi and P. Arulselvan, Natural phyto-bioactive compounds for the treatment of type 2 diabetes: inflammation as a target, Nutrients 8 (2016) Article ID 461 (28 pages); https://doi.org/10.3390/nu8080461

6. A. Roy and R. Manikkam, Cytotoxic impact of costunolide isolated from Costus speciosus on breast cancer via differential regulation of cell cycle - an in-vitro and in-silico approach, Phytother. Res. 29 (2015) 1532-1539; https://doi.org/10.1002/ptr.5408

7. Q. Zhang, D. Caim and J. Liu, Matrix solid-phase dispersion extraction coupled with HPLC-diode array detection method for the analysis of sesquiterpene lactones in root of Saussurea lappa C. B. Clarke, J. Chromatogr. B 879 (2011) 2809-2814; https://doi.org/10.1016/j.jchromb.2011.08.008

8. H. W. Park, J. H. Lee, S.-U. Choi, N.-I. Baek, S.-H. Kim, J. H. Yang and D. K. Kim, Cytotoxic germacranolide sesquiterpenes from the bark of Magnolia kobus, Arch. Pharm. Res. 33 (2010) 71-74; https://doi.org/10.1007/s12272-010-2227-5

9. A. Rasul, B. Yu, L. Yang, M. Arshad, M. Khan, T. Ma and H. Yang, Costunolide, a sesquiterpene lactone induces G2/M phase arrest and mitochondria-mediated apoptosis in human gastric adenocarcinoma SGC-7901 cells, J. Med. Plants Res. 6 (2012) 1191-1200; https://doi.org/10.5897/ JMPR11.922

10. A. Robinson, T. V. Kumar, E. Sreedhar, V. G. M. Naidu, S. R. Krishna, K. S. Babu, P. V. Srinivas and J. M. Rao, A new sesquiterpene lactone from the roots of Saussurea lappa: structure-anticancer activity study, Bioorg. Med. Chem. Lett. 18 (2008) 4015-4017; https://doi.org/10.1016/j.bmcl.2008.06.008

11. P. R. Vadaparthi, C. P. Kumar, K. Kumar, A. Venkanna, V. L. Nayak, S. Ramakrishna and K. S. $\mathrm{Babu}$, Synthesis of costunolide derivatives by Pd-catalyzed Heck arylation and evaluation of their cytotoxic activities, Med. Chem. Res. 24 (2015) 2871-2878; https://doi.org/10.1007/s00044-015-1337-5

12. J. R. Woods, H. Mo, A. A. Bieberich, T. Alavanja and D. A. Colby, Amino-derivatives of the sesquiterpene lactone class of natural products as prodrugs, Med. Chem. Commun. 4 (2013) 27-33; https:// doi.org/10.1039/C2MD20172K

13. A. H. El-Far, H. M. Shaheen, A. W. Alsenosy, Y. S. El-Sayed, S. K. Al Jaouni and S. A. Mousa, Costus speciosus: Traditional uses, phytochemistry, and therapeutic potentials. Pharmacogn. Rev. 12 (2018) 120-127; https://doi.org/10.4103/phrev.phrev_29_17

14. J. Eliza, P. Daisy and S. Ignacimuthu, Antioxidant activity of costunolide and eremanthin isolated from Costus speciosus (Koen ex. Retz) Sm., Chem. Biol. Interact. 188 (2010) 467-472; https://doi. org/10.1016/j.cbi.2010.08.002

15. M. F. Mahomoodally, Quantitative ethnobotanical study of common herbal remedies used against 13 human ailments catergories in Mauritius, Afr. J. Tradit. Complement. Altern. Med. 11 (2014) 1-32; https://doi.org/10.4314/ajtcam.v11i6.1

16. R. K. Upadhyay and S. Ahmad, Ethno-medicinal plants and their pharmaceutical potential, J. Pharm. Res. 5 (2012) 2162-2173.

17. S. O. Onoja and A. O. Anaga, Evaluation of the antidiabetic and antioxidant potentials of methanolic leaf extract of Helianthus annuus L. on alloxan-induced hyperglycemic rats, Comp. Clin. Pathol. 23 (2014) 1565-1573; https://doi.org/10.1007/s00580-013-1824-3

18. Y. Bibi, S. Nisa, F. M. Chaudhary and M. Zia, Antibacterial activity of some selected medicinal plants of Pakistan, BMC Complement. Altern. Med.11(2011) Article ID 52; https://doi.org/10.1186/14726882-11-52 
19. S. O. Onoja, M. I. Ezeja, Y. N. Omeh and B. C. Onwukwe, Antioxidant, anti-inflammatory and antinociceptive activities of methanolic extract of Justicia secunda Vahl leaf, Alexandria J. Med. 53 (2017) 207-213; https://doi.org/10.1016/j.ajme.2016.06.001

20. L. Marcocci, J. J. Maguire, M. T. Droylefaix and L. Packer, The nitric oxide-scavenging properties of Ginkgo biloba extract EGb 761, Biochem. Biophys. Res. Commun. 201 (1994) 748-755; https://doi. org/10.1006/bbrc.1994.1764

21. H. Sebai, S. Selmi, K. Rtibi, N. Gharbi and M. Sakly, Protective effect of Lavandula stoechas and Rosmarinus officinalis essential oils against reproductive damage and oxidative stress in alloxaninduced diabetic rats, J. Med. Food 18 (2015) 241-249; https://doi.org/10.1089/jmf.2014.0040

22. F. Bohlmann, G. Schmeda-Hirschmann and J. Jakupovic, Heliangolides and germacrolides from Disynaphia multicrenulata, Phytochemistry 23 (1984) 1435-1437; https://doi.org/10.1016/S00319422(00)80481-1

23. T. Konishi, Y. Shimada, T. Nagao, H. Okabe and T. Konoshima, Antiproliferative sesquiterpene lactones from the roots of Inula helenium, Biol. Pharm. Bull. 25 (2002) 1370-1372; https://doi. org/10.1248/bpb.25.1370

24. J. Eliza, P. Daisy, S. Ignacimuthu and V. Duraipandiyan, Normo-glycemic and hypolipidemic effect of costunolide isolated from Costus speciosus (Koen ex. Retz.) Sm. in streptozotocin-induced diabetic rats, Chem. Biol. Interact. 179 (2009) 329-334; https://doi.org/10.1016/j.cbi.2008.10.017

25. K. Fukuda, S. Akao, Y. Ohno, K. Yamashita and H. Fujiwara, Inhibition by costunolide of phorbol ester-induced transcriptional activation of inducible nitric oxide synthase gene in a human monocyte cell line THP-1, Cancer Lett. 1 (2001) 7-13; https://doi.org/10.1016/S0304-3835(00)00704-7

26. M. Taniguchi, T. Kataoka, H. Suzuki, M. Uramoto, M. Ando, K. Arao, J. Magae, T. Nishimura, N. Ōtake and K. Naga, Costunolide and dehydrocostus lactone as inhibitors of killing function of cytotoxic T lymphocytes, Biosci. Biotechnol. Biochem. 59 (1995) 2064-2067; https:// doi.org/10.1271/ bbb. 59.2064 